\title{
VIVÊNCIA DE VOZ COM PROFISSIONAIS DE UM HOSPITAL: RELATO DE EXPERIÊNCIA
}

\section{Group of voice with professionals of a hospital: experience report}

\author{
Regina Zanella Penteado (1), Edileine Stenico (2), Fernanda Arancibia Ferrador ${ }^{(3)}$, \\ Neusa Cristina Anselmo ${ }^{(4)}$, Pamela Cristina da Silva ${ }^{(5)}$, Priscila Fabiana Agostinho Pereira ${ }^{(6)}$, \\ Rose Mary Queiroz Galdino ${ }^{(7)}$, Tânia Alessandra de Almeida Bragion ${ }^{(8)}$
}

\begin{abstract}
RESUMO
Objetivo: apresentar o relato de experiência de um grupo de Vivência de Voz realizado por fonoaudiólogos com profissionais e trabalhadores de um hospital. Métodos: análise retrospectiva do processo de um Grupo de Vivência de Voz realizado com 20 profissionais de um hospital do interior de São Paulo, com foco analítico nos objetivos e atividades realizadas. Resultados: foram contemplados os seguintes temas e objetivos: percepções dos sujeitos acerca da própria voz; uso profissional da voz e contextos e condições de trabalho; aquecimento vocal; impactos da voz/fala/comunicação/linguagem e da expressividade nas relações profissionais; possibilidades de mudanças. As ações educativas, contextualizadas nas condições, ambiente e organização do trabalho, possibilitaram gerar espaços de descobertas e de construção coletiva do conhecimento acerca do processo de trabalho no hospital e o grupo se mostrou como espaço social importante e efetivo para a sensibilização dos profissionais e trabalhadores do hospital em relação à voz/saúde vocal e aos seus impactos nas interações e nos processos comunicativos implicados no trabalho em saúde. Conclusão: afirma-se a importância da Fonoaudiologia na promoção de ambientes saudáveis e de processos comunicativos favoráveis à humanização das relações e melhoria do acesso e qualidade no acolhimento e atendimento em saúde.
\end{abstract}

DESCRITORES: Voz; Promoção da Saúde; Educação em Saúde; Comunicação

\section{INTRODUÇÃO}

Os grupos de Vivência de Voz integram as ações da disciplina Estágio em Fonoaudiologia Comunitária I e II do Curso de Fonoaudiologia da UNIMEP/

(1) Fonoaudióloga; Docente do Curso de Fonoaudiologia da Universidade Metodista de Piracicaba, UNIMEP, Piracicaba, SP; Especializanda em Ergonomia pela Universidade Metodista de Piracicaba; Especialista em Linguagem; Especialista em Voz; Doutora em Saúde Pública pela Faculdade de Saúde Pública da Universidade de São Paulo.

(2) Fonoaudióloga da Associação de Pais e Amigos de Surdez de Piracicaba, APASPI, Piracica, SP.

(3) Fonoaudióloga Clínica Policlin.

(4) Fonoaudióloga; Funcionária da Faculdade de Engenharia, Arquitetura e Urbanismo da Universidade Metodista de Piracicaba, UNIMEP, Piracicaba, SP.

(5) Fonoaudióloga Clínica.

(6) Fonoaudióloga.

(7) Fonoaudióloga.

(8) Fonoaudióloga Clínica.

Conflito de Interesses: Inexistente
Piracicaba e são conduzidos por alunos do último ano do curso, sob supervisão de docentes especialistas em voz e desenvolvidos de maneira processual, em encontros semanais de uma hora e meia de duração. Destes grupos participam pessoas de todas as idades que fazem uso profissional ou cotidiano da voz, interessadas em conhecer, aprimorar, cuidar da voz, promover a sua saúde e desenvolver a sua expressividade. Nestes grupos, a voz é trabalhada de maneira coletiva, sob uma perspectiva que considera as suas condições de produção, ou seja, que leva em conta aspectos da subjetividade, da historicidade, da cultura, do ambiente social e profissional e da qualidade de vida dos sujeitos. $O$ trabalho é desenvolvido por meio de ações educativas de característica dialógica, democrática, participante, problematizadora e transformadora que possibilitam, a tais grupos, constituírem-se como espaços sociais de ensino-pesquisa-extensão com potencial para favorecer processos de mudanças, trocas de experiências, vivência, reflexão, criação 
de vínculos e de interação entre os participantes de maneira a contribuir para a sistematização de novas práticas educativas em saúde vocal que, pautadas pelo diálogo entre universidade e a comunidade e pela troca de saberes acadêmico/científico e comunitário/popular, se mostrem condizentes com a proposta de Promoção da Saúde ${ }^{1-6}$.

Os grupos e vivência de voz podem ser realizados em diversos equipamentos de saúde e educação, assim como em setores ligados à produção cultural, serviços, indústria, comércio e outros.

$\mathrm{Na}$ área da saúde, especificamente no que diz respeito à atuação fonoaudiológica hospitalar, a literatura é rica na descrição de experiências junto a setores como maternidade (alojamento conjunto, UTI neo-natal, berçário normal e de alto risco), pediatria, neurologia, oncologia, centro de atendimento intensivo e enfermaria, bem como ambulatorial, na avaliação, orientação e acompanhamento clínico interdisciplinar pré e pós cirúrgicos e terapêuticos a pacientes internos e externos do hospital ${ }^{7}$.

Não se trata do foco deste artigo abordar os trabalhos em Fonoaudiologia Hospitalar, mas vale ressaltar que o foco das intervenções em hospitais está sempre centrado nos pacientes e/ou usuários dos serviços da instituição e seus familiares.

Não são encontrados trabalhos fonoaudiológicos realizados em hospitais que estejam voltados para a promoção da saúde e comunicação dos seus profissionais. É neste sentido que o presente estudo se volta para trabalhadores de um hospital na perspectiva da promoção da saúde vocal, da comunicação e expressividade para melhoria das suas condições de trabalho, saúde e qualidade de vida já que o produto do trabalho, em um serviço especializado de saúde, é um serviço que se dá, basicamente, pela troca de informações e pelo atendimento às necessidades e expectativas dos usuários, sendo que as relações sociais e comunicativas se sobressaem ${ }^{8}$.

Recentemente é observada a preocupação incisiva dos profissionais e serviços de saúde voltada para a qualidade do acesso, desenvolvimento de práticas integrais e acolhimento aos usuários. $O$ acolhimento é uma postura do profissional de saúde perante o usuário e uma estratégia de mudança do processo de trabalho em saúde que incorpora as relações humanas e busca alterar as relações entre trabalhadores/usuários e dos trabalhadores entre si, humanizar a atenção, a recepção e o atendimento, estabelecer vinculação e responsabilização das equipes com os usuários, aumentar a capacidade de escuta às demandas, valorização das queixas apresentadas, solidarização com o sofrimento e de identificação de necessidades e resposta positiva, com valorização dos pressupostos da transdisciplinaridade e do trabalho em equipe ${ }^{8-11}$. O acesso e o acolhimento têm se mostrado como elementos essenciais para a avaliação da qualidade dos serviços de saúde, contribuindo para a satisfação e procura dos usuários pelos serviços ${ }^{9}$.

Entende-se como essencial e necessário um trabalho voltado para a promoção da comunicação e a congruência na expressividade corpo-voz de profissionais da saúde em um contexto hospitalar, na perspectiva de contribuir para a qualidade do acesso, integralização, acolhimento e humanização das relações destes com os usuários e demais profissionais e trabalhadores ${ }^{12,13}$.

A Fonoaudiologia, por atuar com o homem enquanto ser comunicativo, que tem na linguagem o seu instrumento simbólico de relação social e mediação com o mundo, de ação e transformação sobre a realidade e de constituição da própria subjetividade, representa uma área importante com potencial para o desenvolvimento da humanização das relações e promoção da saúde do trabalhador, especialmente quando a atividade profissional envolve processos comunicativos e interacionais que se apóiam na linguagem oral, que envolve o uso da voz e da fala, com ênfase na expressividade corpo-voz. Isso implica na necessidade da comunicação ser pensada em relação à saúde geral, trabaIho e qualidade de vida das pessoas ${ }^{14,15}$.

O objetivo deste artigo é apresentar o relato de experiência de um grupo de Vivência de Voz realizado com profissionais e trabalhadores de um hospital.

\section{MÉTODOS}

Trata-se de um estudo de caso de um Grupo de Vivência de Voz-análise retrospectiva do processorealizado com profissionais de um hospital tradicional, de grande porte e referência regional, localizado no município de Piracicaba (SP), que atende a usuários do Sistema Único de Saúde, conveniados e particulares.

O grupo de Vivência de Voz integrou as ações da disciplina Estágio em Fonoaudiologia Comunitária II do Curso de Fonoaudiologia da UNIMEP/Piracicaba no segundo semestre de 2006 , sendo sete estagiárias sob supervisão docente.

O grupo foi desenvolvido de maneira processual, ao longo de sete semanas durante os meses de outubro a dezembro, sendo cada encontro com duração de uma hora e quinze minutos. Os encontros foram realizados nas dependências do próprio hospital, em um local destinado a atividades de convivência dos funcionários, sendo este um galpão coberto, com banheiros, pias, palco, mesas, cadeiras, quadro-negro e bebedouro. O galpão situava-se em uma área verde próxima ao prédio da lavanderia 
do hospital, defronte a um campo de futebol, em local ajardinado, tranqüilo, arejado e aprazível.

O recrutamento dos sujeitos participantes se deu via setor administrativo e de recursos humanos do hospital, que convidou alguns profissionais dos diversos setores e os dispensou, durante o seu expediente de trabalho, para que pudessem frequentar o grupo. Vale destacar que foi levado em conta o turno de expediente e as escalas de trabaIho, já que a intenção era que o funcionário pudesse participar durante o seu horário de trabalho, evitando a necessidade de deslocamentos específicos para este fim e também considerando que os setores não poderiam ficar descobertos ou parar de funcionar. O grupo de vivência de voz contou com a participação de 20 profissionais e funcionários de diversos setores do hospital: recepção, telefonista, secretaria, internação (emissão de guias), emergência, faturamento e cobrança, PABX, enfermaria, serviço social, plano de saúde (interno e visitas externas), cirurgia plástica e outros serviços vinculados ao hospital - além das estagiárias de Fonoaudiologia e da docente supervisora.

Os dados para a análise do processo de grupo de Vivência de Voz foram obtidos a partir da análise documental do relatório de atividades da disciplina e complementados com informações de observação, anotações e registros fotográficos, todos realizados pelas alunas/estagiárias sob supervisão da professora, ao longo do estágio. São descritos os sete encontros com destaque para os objetivos específicos de cada encontro e as atividades realizadas.

Sendo este um estudo qualitativo, é realizada a análise retrospectiva do processo do grupo de vivência de voz, a qual recai sobre as ações educativas em saúde vocal realizadas em cada encontro.

O estudo integra a pesquisa "A cultura popular no contexto dos grupos de vivência de voz: repensando a ação educativa em saúde vocal" - aprovação CEP/Unimep (76/2004).

\section{RESULTADOS}

A apresentação dos resultados se dá com foco em cada encontro, com destaque para os objetivos e ações realizadas.

\section{Primeiro Encontro}

Objetivos: Apresentação dos participantes para a constituição do grupo; levantamento de percepções dos sujeitos acerca da própria voz (imagem vocal, queixas, necessidades e interesse pelo aprimoramento vocal) e demandas de uso profissional da voz aliadas ao conhecimento de aspectos do ambiente, condições e organização do trabalho.
Ações realizadas: Estando todos acomodados em círculo, os sujeitos se apresentaram falando nome, função ou setor no qual trabalha e resposta para a pergunta "Qual a importância da voz?". A seguir realizou-se uma dinâmica de desenho e depoimento escrito sobre a voz e um desenho esquemático sobre o seu espaço e ambiente de trabalho. Todos apresentaram os desenhos explicando-os, dando seu depoimento e falando sobre o seu contexto de trabalho. Obteve-se que os sujeitos usam a voz no trabalho, variando de 5 a 8 horas por dia em ambientes ruidosos, com ar condicionado e muitas vezes sob relações sociais tensas (usuários e familiares nervosos, impacientes, ansiosos, por vezes assumindo comportamentos agressivos).

Cabe destacar que alguns sujeitos já se conheciam e outros até trabalhavam no mesmo setor; entretanto, para muitos, apesar de funcionários do mesmo hospital, foi uma surpresa conhecer pessoalmente colegas de trabalho com os quais até então só haviam tido contatos de trabalho via $\mathrm{PABX}$, telefone, auto-falante interno ou mesmo via memorandos.

Foram frequentes as queixas vocais de desconforto no uso da voz, garganta seca ou irritada, rouquidão, perda da voz e "as pessoas não entendem o que eu falo". Nenhum sujeito referiu realizar cuidados com a voz/saúde vocal.

Quanto aos desenhos e depoimentos sobre a voz, predominou a imagem vocal/valoração positiva da voz e, quanto aos atributos vocais, apenas uma minoria mencionou os atributos sócio-cultural (relacionado à interação social, às atividades de grupos sociais, comunitárias e culturais) e profissional (relacionado aos traços e opções de acordo com a profissão e as necessidades profissionais) ${ }^{16}$, expressos nas Tabelas 1 e 2.

\section{Segundo, terceiro e quarto encontros}

Objetivos: Trabalhar o aquecimento vocal; levantamento dos usos profissionais da voz nos contextos de trabalho; despertar a atenção dos sujeitos para o uso da voz profissional e para a qualidade vocal e os seus possíveis impactos nas relações; realizar a avaliação vocal dos participantes e apontar possibilidades de mudanças.

Ações realizadas: Iniciou-se abordando a importância do aquecimento vocal, com a realização de exercícios corporais (rotação de ombros, movimentos de cabeça) e vocais (emissão do fricativo sonoro /z/ e mascado vocal em tom habitual, estalo e rotação de língua associado a sons nasais com variação de loudness, vibração de lábio e língua em tom habitual e em escalas ascendente e descendente). 
Tabela 1 - Resultados de depoimentos sobre a voz conforme 0 atributo sócio-cultural

\begin{tabular}{|c|c|}
\hline Suj. & Depoimento \\
\hline 5 & $\begin{array}{c}\text { "eu falo bastante e falo alto. Por causa } \\
\text { disso as pessoas pensam que eu estou } \\
\text { nervosa e estressada" }\end{array}$ \\
\hline 8 & $\begin{array}{l}\text { "eu falo o tempo todo, eu falo muito e às } \\
\text { vezes corto a frente dos outros. Eu acho } \\
\text { que às vezes acabo irritando as pessoas" }\end{array}$ \\
\hline 11 & $\begin{array}{c}\text { "a minha voz pode trazer tranqüilidade } \\
\text { às outras pessoas" }\end{array}$ \\
\hline 13 & "a voz é o meu melhor meio de expressão" \\
\hline 14 & $\begin{array}{l}\text { "a minha voz é irritante e estridente } \\
\text { e causa apreensão nas pessoas" }\end{array}$ \\
\hline 16 & $\begin{array}{c}\text { "acho a minha voz comunicativa } \\
\text { e verdadeira" }\end{array}$ \\
\hline
\end{tabular}

Tabela 2 - Resultados de depoimentos sobre a voz conforme $o$ atributo profissional

\begin{tabular}{cc}
\hline Suj. & Depoimento \\
\hline 5 & "eu dependo dela para o trabalho" \\
8 & "vejo a comunicação indispensável \\
& no meu trabalho" \\
19 & "é o meu meio de comunicação \\
no trabalho"
\end{tabular}

A atividade proposta nos três encontros foi apresentarem uma dramatização individual de uma situação típica de trabalho em que fazem o uso da voz.

Inicialmente os sujeitos descreviam a situação de trabalho seguida pela dramatização. Algumas vezes os colegas participavam da dramatização, fazendo o papel coadjuvante. Foram dramatizadas situações variadas, tais como: Plano de saúde - atendimento pessoal no balcão e informações sobre o convênio pelo telefone; Setor de Cobrança - cobrança de título por telefone; Recepção - informações e entrega de crachás aos visitantes e solicitação de vaga para internação, por telefone; Serviço social - comunica óbito a um familiar; Internação - agenda cirurgia pelo SUS; telefonista - atendimento ao telefone; telefonista e PABX - interagem anunciando chamada telefônica, dentre outras. Aspectos das condições e organização do trabalho eram explicitados por meio das dramatizações.

Ao final de cada dramatização era aberto um espaço para reflexão e discussão coletiva, no qual os participantes eram incitados a expressar as suas percepções e comentários sobre as relações voz x situação de trabalho. As estagiárias apontavam aspectos dos diversos parâmetros vocais por elas avaliados e aqueles percebidos pelos sujeitos do grupo, os quais poderiam ser modificados e melhorados em cada sujeito e, quando pertinentes, comentavam aspectos de psicodinâmica vocal e das intenções, emoções e sentimentos, contexto comunicativo, conteúdo da mensagem e relações interpessoais, na perspectiva do acesso e do acolhimento em saúde.

\section{Quinto e sexto encontros}

Objetivos: Abordar o tema da saúde vocal e aprimoramento da expressividade vocal e corporal.

Ações realizadas: Os encontros iniciavam-se com o aquecimento vocal. No quinto encontro foi realizada a dinâmica do barbante - de posse de um rolo de barbante, cada integrante vai jogando o rolo para os demais participantes de maneira a permanecerem segurando uma ponta do barbante até que se constitua uma grande teia. Ao receber o rolo de barbante nas mãos os sujeitos ganham a palavra e falam sobre aspectos positivos e negativos da sua saúde vocal, explicitando saberes, práticas, hábitos, comportamentos e cuidados com a voz.

A dinâmica mostrou que, apesar de se tratar de trabalhadores da saúde, a maioria desconhece os cuidados com a voz e apresenta hábitos vocais negativos como o grito, o fumo, a ingestão de café, refrigerantes, gelados, alimentos condimentados e apimentados e/ou auto-medicação com uso de soluções bucais gargarejadoras, pastilhas e analgésicos. Diversas substâncias e soluções ingeridas integram o repertório dos saberes e práticas populares, como mascar gengibre, fazer gargarejo com água oxigenada e sal, chás, dormir com um pano com álcool no pescoço. Dentre os poucos cuidados realizados encontram-se: ingerir água (12 sujeitos), maçã (5), fazer aquecimento antes de cantar (2), evitar pigarrear (1) e evitar gelados (1).

No sexto encontro foi dada continuidade à discussão sobre saúde vocal e puderam ser esclarecidos alguns pontos das práticas populares e dos mitos acerca do tema, afirmando os cuidados favoráveis e os hábitos desfavoráveis do ponto de vista fonoaudiológico.

Ainda no sexto encontro foi realizada uma dinâmica de expressividade vocal e corporal, tendo por base uma frase proferida pela enfermeira Maria Júlia Paes da Silva: "Para escrever a simples história de um hospital é preciso conhecer as pessoas, estar atenta a elas, ter alma aberta para o que elas são capazes de expressar pela fala e pelos gestos". Durante a atividade eram resgatados os aspectos da avaliação vocal, apontados a cada sujeito na 
dramatização da situação de trabalho, e observadas as mudanças ocorridas com vistas ao aprimoramento da expressividade.

\section{Último encontro}

Objetivos: Refletir sobre o processo vivenciado indicando as mudanças percebidas.

Ações realizadas: Solicitou-se que os sujeitos expressassem, espontaneamente, as suas impressões, comentários, críticas e sugestões a respeito da Vivência de Voz e que destacassem as mudanças percebidas em prol da qualidade e saúde vocal e expressividade, assim como dos impactos destas no seu trabalho e qualidade de vida.

A telefonista passou a valorizar aspectos de postura e de expressividade corporal; uma secretária passou a aumentar a loudness na comunicação pessoal e ao telefone e passou a hidratar-se constantemente pela ingestão de água além de outros cuidados de saúde vocal; uma recepcionista melhorou a articulação e reduziu a velocidade de fala, que era aumentada e percebeu melhora na inteligibilidade da sua fala; enquanto que a outra de mesma função referiu que passou a explorar a postura e a expressividade facial, o sorriso e o olhar no processo comunicativo além de aumentar a loudness e de praticar o aquecimento vocal; PABX procurou reduzir um pouco a velocidade de fala e usar o sorriso; dentre outras colocações dos sujeitos.

Em geral todos avaliaram positivamente a iniciativa da Vivência de Voz e consideraram a experiência rica e produtiva, solicitando a continuidade do grupo no ano seguinte.

\section{DISCUSSÃO}

Várias autoras ${ }^{5,6}$ destacam a importância das estratégias educativas que levam em conta a subjetividade, os conhecimentos, saberes, experiências e o ponto de vista dos sujeitos sobre a sua própria voz/saúde vocal. Neste sentido, o emprego do desenho e do depoimento escrito sobre a voz, logo no primeiro encontro, pode ser considerado positivo, já que estes recursos vêm sendo apontados como importantes oportunidades do sujeito pensar sobre a voz, as suas características e os aspectos intervenientes na qualidade e saúde vocal, bem como de expressar o conhecimento, a experiência e as percepções relacionadas à voz e de refletir sobre estes ${ }^{16,17}$.

A proposta de se ampliar o esquema do desenho para o ambiente/situação de trabalho e a possibilidade de se pensar e se falar sobre ele aponta um caminho para se conhecer os participantes a partir dos usos da voz na relação com os contextos, ambientes, condições e organização do trabalho incluindo as tensões nas relações ${ }^{14,15}$. A importância de ações neste sentido é afirmada quando a análise das verbalizações dos sujeitos (Tabelas 1 e 2) mostra que os atributos sócio-cultural e profissional foram pouco referidos pelos sujeitos, indicando que, em geral, eles não estão dando a devida atenção, estabelecendo relações ou não estão atribuindo importância para a voz/comunicação e as relações interpessoais e o desempenho profissional. As queixas vocais, em geral restritas às percepções auditivas-proprioceptivas, também se encontram nos limites individuais e não atingem a percepção dos possíveis impactos nas relações interpessoais e profissionais.

Quando se trata de promover o acesso e o acoIhimento em saúde, bem como a humanização das relações, afirma-se a importância da voz, da fala, da comunicação, da linguagem ${ }^{8,12,13}$. Nesta perspectiva, afirmam-se os aspectos de psicodinâmica vocal e impactos da voz sobre as pessoas, especialmente quando se trata a atenção em saúde e das relações entre profissionais da saúde e usuários dos serviços: "a minha voz pode trazer tranqüilidade às outras pessoas" (S.1). Cabe, ainda, destacar que alguns trabalhadores apresentam necessidades referentes ao atributo sócio-cultural e vêm enfrentando dificuldades expressivas, com impactos negativos nas relações interpessoais - o que se configuraria um problema. Isto se torna evidente nas seguintes verbalizações: "eu falo bastante e falo alto. Por causa disso as pessoas pensam que eu estou nervosa e estressada" (S.5); "eu falo o tempo todo, falo muito; e às vezes corto a frente dos outros; eu acho que às vezes acabo irritando as pessoas (S.8); "a minha voz é irritante e estridente e causa apreensão nas pessoas" (S.14).

Entende-se, portanto, que as ações e dinâmicas empregadas no primeiro encontro se mostram como facilitadoras de um processo educativo em saúde vocal que propende à auto-percepção, à reflexão, à participação e à integração dos trabalhadores e dos serviços (já que o grupo de vivência de voz possibilitou, a muitos, que se conhecessem pessoalmente bem como conhecer um pouco mais sobre o setor/ função/trabalho do outro, com as dificuldades a ele inerentes, colaborando para uma compreensão ampliada do processo de trabalho no hospital).

Quanto à proposta da dramatização da situação de uso profissional da voz, desenvolvida no decorrer do segundo, terceiro e quarto encontro, esta pode ser considerada uma estratégia educativa interessante para a formulação das relações entre voz e trabalho, bem como para motivar a ação grupal participativa e para embasamento 
do desenvolvimento das percepções, reflexões e discussões orientadas pela contextualização da voz no trabalho em saúde ${ }^{14,15}$, especialmente nas situações em que o fonoaudiólogo se depara com a impossibilidade da observação da situação real de trabalho de todos os sujeitos. As dramatizações permitem que as discussões a respeito dos dados de avaliação vocal, psicodinâmica e usos profissionais da voz sejam ampliados, na perspectiva de se promover a qualidade das relações interpessoais no trabalho, o acesso e o acolhimento em saúde, evidenciando um alargamento do foco dos trabaIhos tradicionalmente realizados em voz profissional e mostrando caminhos possíveis na perspectiva de uma ação educativa em saúde vocal e em saúde do trabalhador coerente com a proposta de promoção da saúde e de formação de ambientes saudáveis 1,4,18-25. $^{2}$

Quanto ao tema da saúde vocal, abordado no quinto e sexto encontros, nota-se que a proposta da dinâmica do barbante apresenta um diferencial frente às ações educativas tradicionalmente empregadas pela Fonoaudiologia, quais sejam: as palestras e os folhetos informativos que costumam assumir, como pontos de partida, o saber acadêmico-científico e as posturas normatizadoras a respeito de hábitos e comportamentos, sob um caráter higienista ${ }^{3}$. Assim, ao empregar a dinâmica o ponto de partida para a discussão acerca da saúde vocal se volta para o conhecimento do saber e as práticas dos sujeitos envolvidos, sem normatizações ou julgamentos prévios, além do que o caráter lúdico da dinâmica favorece a participação ativa e a expressão dos sujeitos valorizando a sua cultura, os seus conhecimentos e interesses e abrindo caminhos para o momento posterior, no qual se dão as trocas de saberes científico e popular ${ }^{5}$. A possibilidade de contar com dois encontros para tratar da temática também afirma a valorização do processo educativo, oportunizando a reflexão e a discussão que favorecem as mudanças. Ou seja: não se trata de informação em saúde, mas sim de reflexão e de discussão a partir da realidade vivida pelos sujeitos, no sentido de se pensar possíveis transformações.

Os relatos do último encontro, em conformidade com dados da avaliação perceptiva-auditiva fonoaudiológica realizada ao longo dos encontros permitem notar que houve mudanças em aspectos isolados dos parâmetros vocais, da expressividade corpo-voz e dos cuidados de saúde vocal. A Vivência de Voz possibilitou despertar a atenção dos sujeitos para os impactos da voz no outro e na qualidade do seu trabalho, ainda que muitos pontos necessitem ser aprofundados e melhor abordados. Neste sentido talvez o aumento do número de encontros poderia ser considerado.

\section{CONCLUSÃO}

O grupo de Vivência de Voz se mostrou como um espaço social importante e efetivo para sensibilizar os profissionais e trabalhadores do hospital em relação à importância da própria voz, cuidados de saúde vocal e, também, à percepção dos impactos da voz, fala, comunicação e linguagem nas interações sociais implicadas no trabalho em saúde. A característica grupal e processual da proposta, ancorada em ações educativas orientadas pelo favorecimento da expressão, do diálogo, da participação, da reflexão e realizadas de maneira contextualizada às condições, ambiente e organização do trabalho, favoreceu descobertas e a construção coletiva do conhecimento acerca do processo de trabalho no hospital, permitindo que trabalhadores dos diversos setores se conhecessem, bem como as suas respectivas atividades. Além disto, se mostrou positiva para favorecer mudanças nas maneiras dos sujeitos perceberem a voz e os seus usos e para promover a melhoria da saúde vocal e da qualidade na comunicação.

A experiência aponta possíveis caminhos nas formas de se atuar em hospitais e em Saúde do Trabalhador, sob uma perspectiva positiva da saúde e de processo saúde-doença aliada a uma concepção que integra voz/comunicação, saúde, trabalho e qualidade de vida, o que contribui para afirmar a importância da Fonoaudiologia na promoção de ambientes saudáveis e de processos comunicativos favoráveis à humanização das relações e melhoria do acesso e qualidade no acolhimento e atendimento em saúde. 


\begin{abstract}
Purpose: to submit a report on the experience of a group of Voice carried through by speechlanguage-pathologists with professionals and workers of a hospital. Methods: a retrospective analysis of the process of a Group of Voice carried through with 20 professionals of a hospital of a São Paulo city, with an analytical focus in the accomplished objectives and activities. Results: the following themes and objectives were contemplated: perceptions of subjects concerning their own voice; the professional use of voice and work contexts and conditions; vocal warming-up; impacts of voice/ speech/communication/language and expressivity in professional relations; possibilities of changes. The educative actions, contextualized in the given conditions, environment and work organization allow us to generate spaces for discoveries and collective construction of knowledge concerning the work process in the hospital; and the group showed being an important and effective social space for sensitize professionals and workers of the hospital regarding voice/vocal health and their impacts in the interactions and communicative processes inherent to the work in the health area. Conclusion: the work point out how important is speech-language-pathology for promoting healthful environments and communicative processes favorable to humanizing the relations and improving the access and quality in health care and assistance.
\end{abstract}

KEYWORDS: Voice; Health Promotion; Health Education; Communication

\section{REFERÊNCIAS}

1. Bicudo-Pereira IMT, Penteado RZ, Marcelo VC. Promoção da saúde e educação em saúde: uma parceria saudável. O Mundo da Saúde. 2000; 24(1):39-44.

2. Marin CR, Chun RY, Silva RC, Fedosse E, Leonelle BS. Promoção da saúde em fonoaudiologia: ações coletivas em equipamentos de saúde e de educação. Rev Soc Bras Fonoaudiol. 2003; 8(1):35-41.

3. Penteado RZ, Chun RYS, Silva R. Do "higienismo" às ações promotoras de saúde: a trajetória em saúde vocal. Dist Comun. 2005; 17(1):9-17.

4. Penteado RZ, Servilha EAM. Fonoaudiologia em saúde pública/coletiva: compreendendo prevenção e o paradigma da promoção da saúde. Dist Comun. 2004; 16(1):107-16.

5. Penteado RZ, Maróstica AF, Dias JC, Soares MA, Oliveira NB, Teixeira V, Tonon VA. Saúde vocal: pensando a ação educativa nos grupos de vivência de voz. Saúde em Revista. 2005; 7(16):55-61.

6. Penteado RZ, Rossi D. Vivência de voz e percepções de professores sobre saúde vocal e trabalho. Saúde em Revista. 2006; 8(18):39-47.

7. Pelegrini APN. Fonoaudiologia hospitalar: reflexões além das fronteiras. Fonoaudiol Bras. 1999; 2(2):40-5.

8. Maciel-Lima SM. Acolhimento solidário ou atropelamento? A qualidade na relação profissional de saúde e paciente face à tecnologia informacional. Cad Saúd Públ. 2004; 20(2):502-11.

9. Ramos DD, Lima MADS. Acesso e acolhimento aos usuários em uma unidade de saúde de Porto
Alegre, Rio Grande do Sul, Brasil. Cad Saúd Públ. 2003; 19(1):27-34.

10. Gomes MCPA, Pinheiro R. Acolhimento e vínculo: práticas de integralidade na gestão do cuidado de saúde em grandes centros urbanos. Interface. 2005; 9(17):287-301.

11. Solla JJSP. Acolhimento no sistema municipal de saúde. Rev Bras Saúde Matern Infant. 2005; 5(4):493-503.

12. Yogo $Y$, Ando M, Hashi A, Tsutsui S, Yamada $\mathrm{N}$. Judgments of emotion by nurses and students given double-bind information on patient's tone of voice and message content. Percept Mot Skills. 2000; 90(3Pt1):855-63.

13. Silva MJP. O papel da comunicação na humanização da atenção à saúde. Bioética. 2002; 10(2):73-88.

14. Gonçalves CGO, Penteado RZ, Silvério KCA. Fonoaudiologia e saúde do trabalhador: a questão da saúde vocal do professor. Saúde em Revista. 2005; 7(15): 45-51.

15. Penteado RZ. Voz e saúde do trabalhador. Rev Soc Bras Fonoaudiol. Edição Especial [CD-Rom]. Salvador; 2006.

16. Pereira PFA, Penteado RZ. Desenhos e depoimentos: recursos para investigação da percepção e do conhecimento vocal. Rev CEFAC. 2007; 9(3):383-96. dx.doi.org/ S1516-18462007000300012

17. Santos LMA, Sanches MH, Chun RYS, Servilha EAM. Promoção da saúde em jornalismo: o conhecimento do aluno de jornalismo sobre sua 
voz. [CD- ROM] Rev Soc Bras Fonoaudiologia: Suplemento Especial; 2004.

18. Westphal MF. O movimento cidades/municípios saudáveis: um compromisso com a qualidade de vida. Ciênc Saúde Coletiva. 2000; 5(1):39-51.

19. Boonekamp GMM, Colomber C, Tomás A, Nuñez A. Healthy cities evaluation: the co-ordinators perspective. Health Promot Int. 1999; 14(2):103-10. 20. Flynn BC, Ray DW, Rider MS. Empowering communities: action research through healthy cities. Health Educ Q. 1994; 21(3):395-405.

21. Hancock T. The evolution, impact and significance of the healthy cities/ healthy communities movement. J Public Health Policy. 1993; 14(1):5-18.
22. Mclntyre L. The evolution of health promotion. Probe. 1992; 26:15-22.

23. Robertson A, Minkler M. New health promotion movement: a critical examination. Health Educ Q. 1994; 21(3):295-312.

24. Minkler M. Health education, health promotion and the open society: an historical perspective. Health Educ Behav. 1989; 16(1):17-30.

25. Wallerstein N. Powerlessness, empowerment, and health: implications for health promotion programs. Am J Health Promot. 1992; 6(3):197-205.

DOI: 10.1590/S1516-18462009005000026

RECEBIDO EM: 03/09/2007

ACEITO EM: 26/05/2008

Endereço para correspondência:

Regina Zanella Penteado

Av 41, 209 ap. 62

Rio Claro - SP

CEP: $13501-190$

E-mail: rzpenteado@ unimep.br 